\title{
Dissonâncias do Programa Tempo de Aprender (SEALF/MEC/2020) com as pesquisas sobre alfabetização
}

Suzana Lopes de Albuquerque ${ }^{1}$

Carlota Boto ${ }^{2}$

\section{Resumo}

O objetivo deste artigo é apresentar dissonâncias conceituais que a Secretaria de Alfabetização (Sealf) do MEC tem adotado a partir da Política Nacional de Alfabetização (2019) e do Programa Tempo de Aprender (2020), desconsiderando as pesquisas científicas realizadas no âmbito das universidades brasileiras. Ao evocar pesquisas internacionais, principalmente do National Reading Painel (2000), a atual Secretaria limita a alfabetização a seu processo metodológico, não levando em conta a importância da dimensão de letramento. Pergunta-se o que está em debate na visão da Sealf, que insiste em não avaliar a importância da formação inicial e continuada de professores de diferentes universidades e de pesquisadores imbuídos de um princípio crítico-político-social, reduzindo o tema a um viés tecnicista do método sintético fônico.

Palavras-chave: Política Nacional de Alfabetização; Programa Tempo de Aprender; Alfabetização; Método Fônico; História da Educação.

\section{Dissonances of the Time to Learn program (SEALF/MEC/2020) with research on literacy}

\section{Abstract}

The objective of this article is to present the conceptual dissonances that the MEC's Secretariat of Literacy has adopted from the National Literacy Policy (2019) and the Time to Learn program (2020), disregarding scientific research carried out within the scope of Brazilian universities at different levels of teacher training. In evoking international research, mainly the National Reading Panel (2000), the current secretariat limits literacy to its methodological process, disregarding the importance of the literacy dimension, leaving the following question: what is under debate in SEALF's view, which insists in disregarding the importance of initial and continuing training for teachers from different universities and researchers imbued with a critical-political-social principle; and reducing the theme to a technicist bias of the synthetic phonics method?

Keywords: National Literacy Policy; Time to Learn Program; Literacy; Phonic Method; History of Education.

\section{Introdução}

A alfabetização é tema prioritário do debate pedagógico. Afinal, uma cultura letrada começa com a habilidade de leitura e de escrita. Nesse sentido, a discussão sobre métodos de

\footnotetext{
${ }^{1}$ Professora do Instituto Federal de Educação (IFG - Câmpus Goiânia Oeste). É líder do Grupo de Estudo Panecástica. suzana.albuquerque@ifg.edu.br.

2 Professora titular da Faculdade de Educação da Universidade de São Paulo (USP), onde leciona Filosofia da Educação. É Bolsista Produtividade PQ1D do CNPq. Integra o conjunto de pesquisadores principais do Projeto Fapesp 18/26699-4, intitulado Saberes e práticas em fronteiras: por uma história transnacional da educação. reisboto@usp.br.
} 
alfabetização percorre a trajetória da história da educação. No caso brasileiro, não foi diferente. O presente artigo tem por objetivo estudar e apresentar as dissonâncias conceituais expostas pela Secretaria de Alfabetização do MEC no tocante à sua Política Nacional de Alfabetização PNA (2019) e ao Programa Tempo de Aprender (2020). Sob as referências teóricas de Soares (1998; 2018), Mortatti (2000), Ferreiro (2018) e Braslavsky (1971), procurou-se analisar os documentos referidos anteriormente à luz da literatura existente no Brasil e do debate pedagógico em solo nacional. Para tanto, recorreu-se à discussão sobre métodos de alfabetização evocando primordialmente Jacotot e Decroly. A Secretaria toma a alfabetização como um processo exclusivamente metodológico, desconsiderando as inúmeras outras variáveis intervenientes no percurso de aquisição da leitura e da escrita.

O secretário de Alfabetização, Carlos Nadalim, é formado em Direito, com Mestrado em Educação; e lançou-se nesse campo da alfabetização a partir de uma revelação transcendental narrada em seu livro As 5 etapas para alfabetizar seu filho em casa - o guia definitivo (2015). Nadalim tinha como experiência uma escola particular de propriedade de sua família, embora não tivesse formação inicial na área de pedagogia para discutir a temática. Ele mesmo reconhece que "não sabia nada de educação de crianças" (NADALIM, 2015, p.8), não sendo partícipe, portanto, das produções e atuações no campo da alfabetização nas escolas públicas brasileiras.

Em seu guia de alfabetização, Nadalim (2015) caracteriza os métodos analíticos e o sintético silábico como ineficientes e "inimigos", adotando a primazia do método fônico como o único eficaz para revelar um segredo que, segundo ele, "as escolas cobram caro para revelar". É preciso que se recorde a história desses métodos. Para tanto, o secretário desconsidera a produção científica brasileira que circula gratuitamente em forma de e-books, artigos editados em periódicos ou apresentados em eventos científicos, demonstrando completo descaso pela produção brasileira acerca da temática da alfabetização.

O presente artigo, que consiste - como já se observou anteriormente - em uma pesquisa documental a partir da história da educação, se propôs a confrontar os documentos impressos da atual política de alfabetização no Brasil com suas heranças históricas. Nesse sentido, reportou-se à memória sobre como surgiu essa discussão, comparando passado e presente, para demonstrar que aquilo que hoje se apresenta como novo tem uma longa estrada que veio antes de si. Primeiramente procurou-se identificar a trajetória do debate sobre os 
métodos de alfabetização no Brasil. Em seguida, o texto traz alguns apontamentos sobre a oposição entre o método global e o método fônico. Finalmente, verificaram-se as dissonâncias teóricas e conceituais da atual Política Nacional de Alfabetização (2019) e do Programa Tempo de Aprender (2019).

\section{A trajetória do debate sobre os métodos de alfabetização no Brasil}

No debate brasileiro sobre a história da alfabetização, parece já um consenso o reconhecimento da legitimidade dos momentos que Mortatti (2000, p.25) apresentou como "cruciais para o movimento histórico em torno da questão dos métodos de alfabetização, assim como para o duplo movimento de constituição apontado anteriormente".

Para a autora, o primeiro momento, situado no último quartel do século XIX, seria representado pela disputa entre os defensores do método português de João de Deus acerca do ensino da leitura, que partia da palavração, e os "partidários dos então tradicionais métodos sintéticos - soletração e silabação - , em que se baseiam as primeiras cartilhas produzidas por brasileiros" (MORTATTI, 2000, p.25).

O segundo momento, que teve início basicamente no período da Primeira República, até os anos 1920, contou com uma intensificada produção de cartilhas brasileiras: algumas delas voltadas para o método analítico e, outras, que insistiam em defender os métodos sintéticos.

O terceiro momento compreende uma relativização da importância do método segundo os termos de Mortatti (2000, p.26). Calcado no reconhecimento de bases psicológicas para o ensino, esse período, que vai dos anos 1920 até os anos 1970, confere hegemonia "às práticas de medida no nível de maturidade necessária à aprendizagem da leitura e escrita e de classificação dos alfabetizandos, de acordo com as quais a importância do método é sistematicamente relativizada e considerada tradicional" (MORTATTI, 2000, p.26).

Finalmente, o quarto momento, que se inicia por volta do final dos anos 70 do século passado, abarca a considerada revolução conceitual do construtivismo e sua disputa com os persistentes e tradicionais métodos e cartilhas já postos no debate pedagógico. 
De uma perspectiva sincrônica, cada um desses momentos cruciais se apresenta como curta duração histórica. Nesse âmbito, relacionam-se dialeticamente diferenças e semelhanças, continuidade e descontinuidade, passado, presente e futuro, permitindo a apreensão de uma unidade prenhe de um sentido particular, a ser buscado em interpretado em sua 'agoridade' nada imóvel. De uma perspectiva diacrônica, cada um desses momentos, dada a descontinuidade de sentidos, apresenta-se como 'causa do movimento', com 'poder de mover', sucedendo-se na longa duração, sem que a passagem de um a outro esteja determinada por um modelo ou lei geral (MORTATTI, 2000, p.27).

Pode-se regressar, entretanto, ainda mais, voltando ao Império brasileiro de meados do XIX, para evocar, a propósito, a disputa metodológica entre a marcha ${ }^{3}$ analítica, sintética ou mista. Naquele período, havia o embate entre método sintético e analítico, que foi acirrado no contexto brasileiro em 1855 por intermédio do português António Feliciano de Castilho ${ }^{4}$ (18001875), defensor do método sintético e fônico de alfabetização, e dos defensores do método analítico proposto pelo francês Jean-Joseph Jacotot ${ }^{5}$ (1770-1840).

O segredo anunciado por Nadalim (2015) é o seguinte: "antes de ensinar às crianças o princípio alfabético, é necessário conduzi-las por cinco etapas": 1aㅡ) Leitura partilhada 2aㅡ) Memória auditiva de curto prazo 3aㅗ Consciência de frases e palavras 4aㅡ) Consciência silábica 5aㅡ) Consciência fonêmica. A confusão metodológica exposta no guia proposto por Nadalim (2015) consiste em afirmar que, por um lado, se trata de um método fônico e crítico ao analítico, e, contraditoriamente, defende a noção do "todo" da leitura de um livro, destacando como pontapé inicial do processo de alfabetização a fase da consciência de frases, palavras e sílabas, antes de apresentar o princípio alfabético em sua base fonética.

Na defesa do "todo" do livro como pontapé inicial do ensino da leitura e da escrita, Nadalim (2015) evoca o princípio dos métodos analíticos, os quais ele considera inimigos e ineficientes. A importância do ato de ler é lembrada como o princípio primeiro para o ensino da alfabetização, conforme a proposta metodológica contida no segredo apontado por Nadalim (2015).

\footnotetext{
${ }^{3}$ Caminho metodológico.

${ }^{4}$ António Feliciano de Castilho (1800-1875) foi um educador português, poeta, bacharel em Direito pela Universidade de Coimbra e sócio da Academia Real das Ciências de Lisboa. Criou um método fônico de ensino da leitura e da escrita: o Método Castilho para o ensino rápido e aprasível do ler impresso, manuscrito, e numeração e do escrever.

5 Jacotot (1770-1840) foi um educador francês, formado na universidade de Dijon, onde, no décimo nono ano, foi professor de latim, em seguida, estudou Direito, tornou-se advogado e, ao mesmo tempo, dedicou grande atenção à Matemática. Jacotot, em seu método de ensinar a ler, adota uma perspectiva analítica.
}

Periódico Horizontes - USF - Itatiba, SP - Brasil - e021021 
Por essa razão é preciso praticar a leitura em voz alta todos os dias. E quando se deve começar a ler para as crianças? Na verdade, os pais podem começar a ler para o filho já no ventre materno. É importante que a leitura seja um hábito diário, num cantinho agradável de sua casa, e com uma rotina bem definida (antes do café da manhã, depois do jantar, por exemplo) (p.21).

Ao reconhecer e sustentar a necessidade da leitura do "todo" do livro desde o ventre materno no âmbito particular e restritivo da família, por similitude, é necessário sustentar que as escolas adotem esse hábito de leitura não no fim das marchas da consciência fonêmica e da relação sonora entre grafema-fonema, das junções das sílabas, palavras e frases, mas no início, como ponto de partida.

Essa prática de leitura do "todo", que vem com o Programa "Conta pra mim"6, da Secretaria de Alfabetização (Sealf), - programa de promoção da Literacia Familiar (2019) —, ressoa, sob nova roupagem, a concepção do letramento, definido como "o resultado da ação de ensinar e aprender as práticas sociais da leitura e escrita; é também o estado ou condição que adquire um grupo social ou um indivíduo como consequência de ter-se apropriado da escrita e de suas práticas sociais" (SOARES, 1998, p.39).

A concepção de alfabetização de Nadalim (2015) adota a matriz do método analítico, apesar de considerá-la ineficiente, por engendrar o hábito da leitura do "todo" dos livros no início do processo de alfabetização da criança e defender a necessidade da formação da consciência de frases e palavras, antes mesmo da introdução da consciência fonêmica, que seria o paradigma escolhido para a adoção do método fônico.

Dessa forma, a ordem no processo de alfabetização defendida no guia de Nadalim (2015) consiste primeiramente na leitura do todo dos livros, depois na tomada de consciência das frases e palavras, uma vez que as frases estariam correlacionadas na cabeça das crianças, e elas articulariam uma palavra com a outra, sem separar os sentidos inscritos na frase. Por isso é importante praticar os exercícios de tomada de consciência das palavras que compõem as frases (NADALIM, 2015).

Com a mesma proposta de decomposição das palavras apresentada no método Castilho, que adentrou no Brasil em 1855, o passo seguinte ao da tomada de consciência das frases (sentenciação), segundo Nadalim (2015), seria a consciência silábica por meio da decomposição das palavras em sílabas através de palmas.

\footnotetext{
6 O Programa "Conta pra mim" se apresenta como um programa de Literacia Familiar. Disponível em: http://alfabetizacao.mec.gov.br/contapramim.
}

Periódico Horizontes - USF - Itatiba, SP - Brasil - e021021 
A atividade desta etapa é bem simples. Você deve segmentar palavras batendo uma palma para cada sílaba ao pronunciá-la, e a criança terá de ser capaz de dizer o número de sílabas da palavra. Use palavras que sejam familiares ao seu filho, como nomes de pessoas da sua família. Por exemplo, "Carlos": Car (uma palma) -los (outra palma) (p.25).

Após a tomada de consciência das sílabas, Nadalim (2015) anuncia, como última etapa do processo, a chegada do momento mais importante das cinco etapas: a tomada de consciência fonêmica, que permite que as crianças tenham mais facilidade de decodificar a sílaba e não o som isolado, afirmativa também na contramão da abordagem fonética, que tem tal som isolado como ponto de partida do ensino.

Nesta quinta etapa, é preciso entender que o fonema é uma realidade intrassilábica, abstrata, que representa padrões articulatórios da fala. O fonema se encontra na mente do falante e se concretiza por meio dos fones (os valores fonológicos a que já me referi antes). Para as crianças tudo isso é muito abstrato. De fato, elas percebem com mais clareza as sílabas do que os fones, pois, ao emitir a voz, elas segmentam as palavras em sílabas, não em fones. Por exemplo, dizem: [ba]-[la], e não [b]-[a]-[l]-[a]. Embora seja demasiado abstrato, é preciso tratar do assunto e conhecê-lo, porque é decisivo para o alto desempenho das crianças em leitura (p.26).

Tais confusões conceituais e metodológicas sobre o processo de alfabetização por parte do guia elaborado pelo secretário de Alfabetização, Carlos Nadalim, reverberam no atual cenário da Secretaria de Alfabetização do MEC, a partir da Política Nacional de Alfabetização e do Programa Tempo de Aprender, principalmente no que tange à tentativa simplista de reduzir um processo que exige a completude do indivíduo em suas questões sociais, históricas, familiares, escolares, dentre outras, à discussão de marcha sintética ou analítica.

\section{Princípios que alicerçaram a oposição entre método global e método fônico: alguns apontamentos}

Jean-Joseph Jacotot, considerado precursor do método global, inicia sua clássica obra sob o título Enseignement universel: langue maternelle, publicada em Paris no ano de $1834-$ apontando que, quando uma pessoa quer se instruir, ela principia por comparar as coisas já 
conhecidas com aquelas com as quais ainda não tem familiaridade (JACOTOT, 1834, p.III). pressuposto desse autor é que a inteligência é igual em todas as pessoas e que essa igualdade das inteligências seria o laço comum do gênero humano (JACOTOT, 1834, p.38). Jacotot, refugiado na Bélgica, em 1818, deveria ensinar na universidade a alunos que tinham no flamengo sua única língua, mas ele não conhecia o flamengo. Jacotot, então, começa a fazer os alunos lerem paralelamente as duas versões da edição bilíngue do Telêmaco de Fénelon. De uma parte do texto que liam, os alunos extraíam seus sentidos, para depois reconhecer os parágrafos, as frases e as palavras. Ou seja: iniciavam-se do todo para a parte. Estavam dados ali os princípios do método global de alfabetização.

Ovide Decroly, em 1904, retomaria a perspectiva de Jacotot e desenvolveria um método de leitura global (que poderia ser também chamado de visual natural, ou de ideovisual, ou, ainda, visual ideográfico). Como observa Amélie Hamaïde (1976), Decroly teria evidenciado que

[...] enquanto uma criança aprende a ler, a compreensão visual dos signos gráficos, a expressão verbal, a associação dos sons, a sua representação gráfica, a cópia, a expressão escrita e a ortografia desses signos formam, antes de tudo, um só e mesmo todo. Ora, a leitura, assim compreendida, necessita da intervenção de funções diferentes: 1) a função visual e verbal; 2) a função auditiva; 3) a função motriz da linguagem e da escrita; 4) uma função superior para a compreensão do texto etc. [...]. Não há, portanto, nada de extraordinário no emprego de um método visual para o ensino da leitura. Mas como aplicar esse método natural? Para encontrar o caminho a seguir, retornemos à psicologia da criança pequena. Vejamos os processos empregados pela mãe para the ensinar a falar. Ela se dirige a ele por letras, por monossílabos, por palavras? Ou antes por frases, por ideias? E não se vê a criança aprender, pouco a pouco, a se exprimir? (p.113-114). ${ }^{7}$

Pode-se também verificar pela leitura do próprio Decroly (2006) a defesa de seu método:

\footnotetext{
7 “(...) lorsqu'un enfant apprend à lire, la compréhension visuelle des signes graphiques, l'expression verbale, l'association des sons et leur représentation graphique, la copie, l'expression écrite et l'ortographe de ces signes ne forment qu'um seul et même tout. Or la lecture comprise ainsi necessite l'intervention de fonctions diferentes: 10. la fonction visuelle et verbale; 2 ㅇ. la fonction auditive; 3‥ la fonction motrice du langage ou de l'écriture; 4‥ une fonction supérieure pour la compréhension du texte etc. (...) II n'y a donc rien d'extraordinaire à l'emploi d'une méthode visuelle pour l'enseignement de la lecture. Mais comment appliquer cette méthode naturelle? Pour trouver la marche à suivre, retournons à la psychologie du jeune enfant. Songeons aux précedés employés par as mère pour lui apprendre à parler. S'addresse-t-elle à lui par letres, par monosyllabes, par mots? Ou bien plutôt par phrases, par idées? Et ne voit-on pas l'enfant parvenir petit à petit à s'exprimer?" (HAMAIDE, 1976, p.113-114).
}

Periódico Horizontes - USF - Itatiba, SP - Brasil - e021021 
O método ideo-visual, no qual se principia pelo emprego da frase da palavra, em vez da letra e da sílaba, é uma aplicação na ordem perceptivo-visual-verbal da atividade globalizadora. Não há análise nos começos, sem aquisições de um grande número de imagens, de frases e de palavras. Para responder às condições favoráveis à atividade globalizadora, tais frases e tais palavras devem referir-se a ideias sugeridas à criança ou concebidas por ela e associar-se a suas emoções, a seus interesses (jogos, alimentos, meios de locomoção, seres vivos, atos e gestos de seus companheiros e dela própria). Pouco a pouco, e na medida da capacidade da criança, a análise se favorecerá pela aproximação das palavras já adquiridas. Vantagens: relação da leitura com a própria vida da criança, possibilidade de tomar os textos de leitura no domínio de seus pensamentos, de unir a leitura, como a linguagem, a sua vida afetiva. A repetição, mais ou menos necessária segundo as crianças, se favorecerá por meio de jogos. Para a comprovação, a leitura em voz alta deve ser substituída, tanto quanto possível por exercícios de leitura inteligente ou de leitura silenciosa, de maneira a que se comprove que a criança mesma pode comprovar os resultados obtidos e as repetições necessárias (p.90-91). ${ }^{8}$

Na mesma época de Decroly, Maria Montessori (2017), outra protagonista do movimento

da Escola Nova, tinha como ponto de partida do processo de alfabetização o som de cada letra.

Note-se que não se tratava de começar o processo de alfabetização pelo nome da letra. O som da letra é que se apresentava como o princípio operatório organizador do método sintéticofônico de Maria Montessori. O princípio aqui era, portanto, oposto àquele que norteava Decroly. Em sua prática de ensino, ela fazia o seguinte, segundo suas próprias palavras:

(...) para traçar os sinais gráficos, apresento à criança um material constituído de pequenos cartões lisos sobre os quais são aplicadas letras do alfabeto, recortadas em folhas de lixa; a criança toca-as no sentido da escrita, repetindo o gesto. $O$ sinal do alfabeto fixa-se assim duplamente na memória, graças à vista e ao tato (MONTESSORI, 2017, p.207).

\footnotetext{
8 "El método ideo-visual en el que se empieza por el empleo de la frase y de la palavra, en vez de la letra y de la sílaba, es una aplicación en el orden perceptivo visual verbal de la actividad globalizadora. No hay análisis en los comienzos, sino adquisiciones de un gran número de imágenes, de frases y de palavras. Para responder a las condiciones favorables a la actividad globalizadora, estas frases y estas palavras deben referirse a ideas sugeridas al niño o concebidas por él y asociarse a sus emociones, a sus interesses (joguetes, alimentos, medios de locomoción, seres vivos, hechos y gestos de sus camaradas y de él mismo). Poco a poco, y en la medida de la capacidade del niño, el análisis se favorecerá por la aproximación de las palavras adquiridas ya. Ventajas: relación de la lectura con la vida mesma del niño, posibilidad de tomar los textos de la lectura en el dominio de sus pensamientos, de unir la lectura, como el lenguage, a su vida efectiva. La repetición, más o menos necessária según los niños, se favorecerá por médio de juegos (asociación de frases y de palavras con escenas en estampas, objetos, personajes, animales, produtos etc.). Para la comprobación, la lectura en alta voz deve ser reemplazada, tanto como sea posible, por ejercicios de lectura inteligente o de lectura silenciosa, de manera que se compruebe y que el niño mismo pueda comprovar los resultados obtenidos y la repeticiones necessárias" (DECROLY, 2006, p.90-91).
}

Periódico Horizontes - USF - Itatiba, SP - Brasil - e021021 
Conforme argumenta Braslavsky (1971, p.53), o método fônico teria a vantagem de ser um método lógico, "que se poderia graduar, com economia de esforços, à criança, para aprender, e, ao mestre, para ensinar". Contudo, a autora ressalta também que não seriam poucas as desvantagens desse método. Em primeiro lugar, há dificuldade quanto à pronúncia das consoantes isoladas. Em segundo lugar, poderá haver falta de interesse por parte dos alunos, dado o excesso de mecanização do método. Diz Braslavsky (1971, p.53) que "a repetição de sons sem sentido adormece a capacidade para compreender o que se lê". E, finalmente, a principal objeção feita ao método fônico diz respeito à dificuldade de sua aplicação em diversos idiomas: "existem muitos idiomas cuja língua escrita tem uma correspondência perfeita de cada letra com cada som, de cada grafema com cada fonema; e, outrossim, há idiomas que oferecem uma correspondência menor" (BRASLAVSKY, 1971, p.54).

Maria do Rosário Longo Mortatti (2000) e Magda Soares (2018) mostram que o debate entre o método analítico (global) e os métodos sintéticos (alfabético, fônico e silábico) prosseguiu até as últimas décadas do século XX, quando, então, basicamente nos anos 1980, surge o construtivismo como uma solução para se combater, nos diferentes países, os ainda elevados níveis de reprovação na aprendizagem inicial da leitura e na escrita. Magda Soares (2018, p.23) considera que o construtivismo "seria não um novo método, mas uma nova concepção do processo de aprendizagem da língua escrita". A mesma autora recorda que:

Nos anos iniciais do século XXI reaparece a discussão sobre métodos na alfabetização, relativamente marginalizada durante as duas últimas décadas do século $\mathrm{XX}$, e enfrentam-se de novo polêmicas, agora mais complexas: não apenas divergências em torno de diferentes métodos de alfabetização, mas também, e talvez, sobretudo, dúvidas sobre a possibilidade ou a necessidade de método para alfabetizar - um movimento de recuperação do método em conflito com a tendência à desmetodização, consequência da interpretação que se deu ao construtivismo (p.24).

Esse dilema sobre a questão dos métodos é o que tem aparecido no debate brasileiro contemporâneo acerca da temática da alfabetização. Este artigo, por exemplo, trata da polêmica a respeito do método de alfabetização proposto pelo Governo Federal brasileiro. 


\section{As dissonâncias da atual Política Nacional de Alfabetização (2019) e do Programa Tempo de Aprender (2019)}

Ao criar uma Secretaria de Alfabetização como parte da estrutura do Ministério da Educação, em 2019, o atual governo desloca a questão do analfabetismo no Brasil da arena sociopolítica e do entendimento de que se trata de um processo que é dialógico, interativo e restrito para um viés tecnicista de adoção de matriz fônica, estando a implementação da PNA em execução por meio do Programa Tempo de Aprender (2020). Indo na contramão das pesquisas científicas construídas ao longo da história da educação no Brasil, tais práticas indicam falta de conhecimento do processo de construção das concepções sobre alfabetização no Brasil, não levando em conta também os professores - sujeitos que, em diferentes níveis e modalidades, possuem uma formação inicial e continuada que engendram essas discussões e que integram o que pode-se chamar de chão das salas de aula públicas.

Sem levar em conta as pesquisas científicas brasileiras publicadas na área da alfabetização e ignorando o papel da Associação Brasileira de Alfabetização (Abalf), a Sealf tem buscado aportes teóricos e metodológicos em outros países, tentando implementar, por meio da Política Nacional de Alfabetização $(2019)^{9}$ e do Programa Tempo de Aprender ${ }^{10}(2020)$, a base de um método fônico, que surgiu no Brasil em 1855, e que retorna agora com o mesmo discurso de adotar uma opção metodológica como a solução regeneradora para o problema do analfabetismo no país.

Ao optar por tal saída metodológica quanto à adoção de uma matriz sintética como a via para superar o analfabetismo no Brasil, esse posicionamento tende a silenciar a complexidade de um processo multifacetado que, dentre inúmeras outras questões, passa pelas solicitações históricas realizadas pelos professores no que tange à melhoria da qualidade do Ensino Fundamental e das "condições de salário e de trabalho; a redução do número de alunos por turma; a ampliação da jornada escolar; o aumento das oportunidades de formação continuada; mais verbas para material didático, livros, bibliotecas e salas de leitura" (CARVALHO, 1994, p.8).

A saída para o analfabetismo no Brasil pretendida por essa nova pasta tem sido tratada

\footnotetext{
${ }^{9}$ Documento disponível em: http://portal.mec.gov.br/images/banners/caderno_pna_final.pdf.

${ }^{10}$ Programa disponível em: http://alfabetizacao.mec.gov.br/tempo-de-aprender.
} 
pelos especialistas sob a restrita visão de uma contenda metodológica, uma vez que a alfabetização encontra-se limitada ao seu ponto de vista operacional, tendo como princípio "a fundamentação em evidências das ciências cognitivas, a ênfase no ensino de seis componentes essenciais para a alfabetização - consciência fonêmica, instrução fônica sistemática, fluência em leitura oral, desenvolvimento de vocabulário, compreensão de textos e produção de escrita" (BRASIL, 2019).

Conforme apresentado no primeiro tópico deste artigo, a Sealf adota na PNA (2019) e no Programa Tempo de Aprender (2020) a matriz do método fônico, apesar das dissonâncias tanto no conceito de tal método sintético quanto em seu desenvolvimento metodológico apresentados no guia do atual secretário de Alfabetização, Carlos Nadalim (2015). A confusão conceitual é perceptível nesse guia que anuncia um método sintético e fônico e que, em sua materialização, possui os pressupostos metodológicos da matriz global ou analítica, por partir do "todo" do método analítico, passando pela leitura do texto (sentenciação), depois pela palavração, para apenas no final introduzir a consciência sonora das palavras.

O Programa Tempo de Aprender, idealizado pela recém-criada Secretaria de Alfabetização, segundo consta em seu slogan no site ${ }^{11}$ do MEC, é uma iniciativa voltada para o apoio e a valorização de professores e gestores das redes públicas de ensino do último ano da pré-escola e do 1으 e 2 o anos do Ensino Fundamental, e objetiva ensinar gerações de cidadãos a ler e a escrever. Ao anunciar uma correção da rota das políticas públicas de alfabetização no país, o Programa remonta ao modelo imperial da base do português António Feliciano de Castilho que, em 1855, propagandeou na corte brasileira o método fônico como a saída para o "mal" do analfabetismo.

Conhecer e ser partícipe do registro historiográfico sobre o processo de alfabetização no Brasil permite compreender que aquele debate do Império, que retorna sob novas roupagens, limita as políticas públicas a uma marcha sintética e fonética, desconsiderando as múltiplas facetas que envolvem o processo de alfabetização, bem como os sujeitos envolvidos.

Apesar de anunciar no vídeo ${ }^{12}$ disponibilizado no portal do MEC uma capacidade de

\footnotetext{
${ }^{11}$ http://alfabetizacao.mec.gov.br/contapramim.

12 Vídeo disponível em: http://portal.mec.gov.br/busca-geral/12-noticias/acoes-programas-e-projetos637152388/85721-mec-lanca-programa-tempo-de-aprender-para-aprimorar-a-alfabetizacao-no-pais.
}

Periódico Horizontes - USF - Itatiba, SP - Brasil - e021021 
autonomia entre os docentes, o Programa Tempo de Aprender está organizado sob a indicação de uma "técnica", conforme os dizeres do mesmo vídeo, de base fonética, indicando-a como única possibilidade já estruturada em sequência no curso de formação continuada em práticas de alfabetização - Tempo de Aprender $-{ }^{13}$, com a ordenação das etapas metodológicas:

1) Aprender a ouvir (sonoridade/pausa/ritmos).

2) Conhecimento alfabético (letras-sons).

3) Fluência (compreender textos).

4) Vocabulário.

5) Compreensão.

6) Produção de escrita.

Observa-se que, como método sintético e fônico, o ato de compreender um texto e a capacidade de produção de escrita são relegados ao fim do processo. $\mathrm{O}$ ato de ler e escrever fica dissociado, sendo que, no primeiro tópico - "Aprender a ouvir" -, está a primazia da consciência das palavras, sílabas e sons, na seguinte ordem:

1) Discriminação de sons.

2) Consciência de palavras (sentenciação).

3) Consciência de sílabas.

4) Consciência de aliterações.

5) Consciência de rimas.

6) Isolamento de sons.

7) Síntese de sons.

8) Segmentação de sons.

9) Substituição de sons.

Observa-se que, para a introdução dos sons, o Programa Tempo de Aprender adota como estrutura básica do ensino da leitura uma frase do cotidiano da criança, remetendo ao método global ou analítico da sentenciação, seguido da consciência silábica e, posteriormente, do código alfabético.

\footnotetext{
${ }^{13}$ Link para o programa de formação continuada em alfabetização sob a base técnica do método fonético. Disponível em: http://alfabetizacao.mec.gov.br/professor-clique-aqui-para-acessar-o-curso-de-formacao.
} 
Basta ter em mente algumas frases simples, de fácil compreensão para crianças. Você pode até utilizar frases que refletem alguma situação real que acabou de acontecer, como "Pedro entregou o caderno." Aproveite todos os momentos para brincar com as crianças e estimule-as para que aprimorem a consciência de palavra (MEC, 2020, módulo 2, episódio 2).

A incongruência apresentada no guia de Nadalim (2015) surge no Programa Tempo de Aprender, no segundo nível do ensino dos sons, uma vez que evoca o princípio da sentenciação, já trabalhado por Jacotot em 1832 e por Decroly que, em 1907, definiu tal metodologia como método global ou analítico. Decroly, inclusive, exemplificou essa atividade de solicitar aos alunos frases de comandos simples para estimular o aprimoramento da aptidão pela palavra.

Para o ensino dos sons, após a consciência da sentença e das palavras, o Programa Tempo de Aprender adota como próximo passo metodológico o ensino da decodificação das sílabas, definidas como pedaços das palavras apresentadas.

Bater palmas é uma estratégia eficaz e muito utilizada no cotidiano da sala de aula. Outra estratégia também eficaz, mas silenciosa, é apoiar o queixo sobre a ponta dos dedos indicador e médio. As crianças devem pronunciar a palavra e contar os movimentos do queixo para descobrir quantas sílabas a palavra tem. A pronúncia pode ser exagerada, para o movimento do queixo ficar mais evidente (MEC, 2020, módulo 2, episódio 4).

Apesar de apresentar a matriz fonética que caminha da menor parte para o todo, conforme os métodos sintéticos, o Programa Tempo de Aprender considera "importante que haja uma progressão: primeiro se toma consciência de que as frases são formadas por palavras, depois de que as palavras são formadas por sílabas, e finalmente, por sons das letras, os quais também chamamos fonemas" (MEC, 2020, módulo 2, episódio 6). Dessa forma, apropria-se da matriz do método analítico do "todo" para o reconhecimento sonoro relegando, porém, o todo da leitura do texto, do mundo representado por palavras e por signos semióticos, e o todo das tentativas de escrita ao final do processo e, claro, se efetivamente restar tempo hábil.

Os processos de reconhecimento dos sons (fonema) e das letras (grafema) encontram-se desacoplados, pois, para o momento de escuta e reconhecimentos dos sons, parte-se do "todo", e, quando se passa ao módulo do conhecimento alfabético, inicia-se o ensino de letras desassociadas desse "todo". Nesse momento, os textos que devem ser lidos, segundo Nadalim 
(2015), desde o ventre materno e as frases são reduzidos a uma ordenação encadeada de apresentação inicialmente das letras, depois sílabas, palavras, conforme apresenta-se a matriz sintética.

Essa cisão entre os processos de reconhecimento de sons (fonemas) e as letras (grafemas) é contraditória até relativamente àquilo que é anunciado pelo próprio Programa, ao defender que "não significa, contudo, que primeiro se aprende a consciência fonêmica, para então avançar. Afinal, o conhecimento do princípio alfabético é favorecido quando ensinado de modo concomitante e associado à consciência fonêmica" (MEC, 2020, módulo 3, episódio 2). Para desenvolver a instrução sistêmica, defende-se partir do todo relacionável de variados tipos de textos, como fazem os métodos analíticos, porém, para o conhecimento alfabético, a marcha a ser seguida compreende as relações fonema-grafema de maneira compartimentada, segmentada, mecânica e desacoplada das práticas de leitura e escrita social.

O Programa anuncia a utilização de práticas integradas, de atividades genuínas de leitura e escrita com palavras contextualizadas, porém observa-se a utilização de frases artificiais, prontas e acabadas.

[...] A melhor maneira de aprender os nomes das letras e seus sons é por meio de práticas integradas, ou seja, atividades genuínas de leitura e escrita com palavras contextualizadas. Por isso, para cada relação letra-som ensinada, vamos disponibilizar uma história e um poema sobre um personagem, de modo que as crianças aprendam em um contexto lúdico e atraente (MEC, 2020, módulo 1, episódio 3).

Não deixando espaço para a produção de textos pelos próprios alunos, é relegada a um segundo plano a vontade de ler, tentar escrever, buscar significados, entrar em contato com diferentes textos impressos e materiais que encontram em seu cotidiano.

Para se tornar alfabetizado, o Programa reduz o processo ao ato mecânico de decodificar, haja vista que o "alfabeto é dotado de um conjunto de regras para que se transite entre os domínios dos sons falados e dos grafemas impressos. Conhecer essas regras permitirá que os alunos se tornem proficientes em leitura e em escrita" (MEC, 2020, módulo 3, introdução). A própria fundamentação teórica utilizada pelo PNA e pelo Programa Tempo de Aprender vale-se 
da referência do National Reading Pane/ ${ }^{14}$ (2000). Não se assegura, com isso, que essa relação de decodificação seja a única capacidade a ser percorrida no processo de alfabetização; e o conhecimento de tais regras não garante a proficiência em leitura e escrita, uma vez que "outros recursos influenciam a leitura e compreensão também como o vocabulário das crianças, seu conhecimento do mundo e sua memória para o texto ${ }^{15 "}$ (NATIONAL READING PANEL, 2000, p.2-5).

Não há como negar a necessidade do letramento para conseguir alcançar essa leitura do mundo e a ampliação do vocabulário das crianças. Com poemas e frases contendo palavras ou letras previamente selecionadas com o mesmo princípio fonético (no método silábico seria a utilização da mesma "família", por exemplo), não serão ampliadas as capacidades de uso social do código escrito que a pesquisa científica internacional citada, em consonância com as pesquisas brasileiras, tem apontado.

Apesar de utilizar os cinco pilares utilizados no Tempo de Aprender - a saber, a consciência fonêmica, a instrução fônica sistemática, a fluência de leitura, o vocabulário e a compreensão de textos -, o National Reading Panel (2000, p.2-6) afirma que "os professores devem reconhecer que a aquisição da instrução fonêmica é um meio e não um fim. $A$ instrução fonêmica não é adquirida por si só, mas pelo seu valor em auxiliar os alunos a entender e usar o sistema alfabético para ler e escrever" ${ }^{\prime 16}$.

Como explicita claramente Magda Soares (2018), as nuances que envolvem a alfabetização estão para além da adoção de uma marcha sintética ou analítica; logo, esse viés reducionista que a atual pasta da Secretaria de Alfabetização tem adotado vai na contramão das pesquisas científicas nacionais e internacionais.

É, portanto, fundamental que, em pesquisas que envolvam crianças das camadas populares, em que o fracasso em alfabetização tradicionalmente se concentra, seja considerada sempre a possível influência da variação linguística

\footnotetext{
${ }^{14}$ Material digitalizado e disponível em: https://www.nichd.nih.gov/sites/default/files/publications/pubs/nrp/Documents/report.pdf. 15 "Other capabilities influence reading comprehension as well, such as children's vocabulary, their world knowledge, and their memory for text" (NATIONAL READING PANEL, 2000, p.2-5).

16 "Teachers should recognize that acquiring phonemic awareness is a means rather than an end. PA is not acquired for its own sake but rather for its value in helping learners understand and use the alphabetic system to read and write" (NATIONAL READING PANEL, 2000, p.2-6).
} 
sobre respostas a tarefas de avaliação e consciência sintática e morfológica, como também, e talvez, sobretudo, deve ser considerada essa influência para a interpretação de pretensas dificuldades de aprendizagem, que, muitas vezes, se explicam pela distância entre a variedade falada pela criança e uma língua escrita que se ensina na variedade culta (SOARES, 2018, p.148).

Tal problemática, evidentemente, ultrapassa as dissensões metodológicas. Não se trata apenas de abordar a temática do método, pautando-se por considerações abstraídas da realidade. É fundamental que se volte para o chão da escola para se pensar as ações para alfabetizar e para ensinar bem. Azanha (2011), acerca do que chamava de "abstracionismo pedagógico", dirá o seguinte sobre essa transformação das questões metodológicas em prioridade do discurso educacional:

\begin{abstract}
Esse estilo configura-se como uma variedade do que se poderia chamar de 'abstracionismo pedagógico', entendendo-se a expressão como indicativa da veleidade de descrever, explicar ou compreender situações educacionais reais, desconsiderando as determinações específicas de sua concretude, para ater-se apenas a princípios ou leis gerais que, na sua abrangência abstrata, seriam, aparentemente, suficientes para dar conta das situações focalizadas. [...] desejamos esclarecer mais detidamente algumas das falhas em que incorre esse estilo de investigação, que, não obstante suas pretensões teóricas, na verdade, não consegue mais do que utilizar-se da teoria disponível (ou melhor, de contrafrações esquemáticas dela) para efetuar operações formais de classificação de fatos da realidade, como se essas operações constituíssem explicações. Assim, a compreensão histórica acaba se resumindo na aplicação de referenciais a uma realidade, na verdade, desconhecida (p.42).
\end{abstract}

Desta forma, urge a necessidade de pensar o processo de alfabetização para além das marchas metodológicas.

\title{
Considerações finais
}

O contexto imperial de confusão metodológica referente aos métodos de ensino e o simplismo de tentar padronizar a questão metodológica como saída para o mal do analfabetismo voltam ao cenário brasileiro a partir da perspectiva da Secretaria de Alfabetização, a qual, após 160 anos, traz novamente a perspectiva, absolutamente ultrapassada, de adotar um método prescritivo engendrado ao processo de alfabetização. 
Se Nadalim (2015) considera a última etapa do processo a apresentação da consciência fonêmica, o Programa Tempo de Aprender inverte sua lógica, mostrando as incoerências de concepções destinadas aos diferentes públicos. Aos alunos que podem ser alfabetizados no âmbito da família, programas como a literacia, a apresentação do "todo" dos livros e materiais impressos e o uso social "desde o ventre materno" são bem-vindos; já para os nossos alunos das escolas públicas aos quais serão destinados o Programa, resta o sibilar de palavras soltas e descontextualizadas de seu contexto social, histórico e político.

Nas incoerências apresentadas no próprio Programa Tempo de Aprender e no guia de alfabetização elaborado pelo secretário da Alfabetização, Carlos Nadalim, em 2015, observa-se, mesmo que haja a negação disso, a concepção de letramento, pois, antes de ensinar a decodificar as letras e sons, é preciso mostrar aos alunos o que se ganha, o que se aprende com a leitura: mas isso só será possível por meio de atividades que façam sentido, que visem à compreensão de leitura desde as etapas iniciais da alfabetização. Destinado aos alunos das escolas públicas, para o ensino do sistema alfabético, o Programa Tempo de Aprender não apresenta textos, leituras, decomposição de frases e palavras com um sentido social. Antes, o processo é dado como se a leitura fosse um ato mecânico, separado da compreensão, por meio de palavras soltas, sílabas isoladas e com repetições sem fim.

A Sealf insiste em desconsiderar a importância da formação inicial e continuada de professores de diferentes universidades e de pesquisadores imbuídos de um princípio críticopolítico-social, reduzindo o processo de alfabetização a um viés tecnicista de um método sintético fônico. Enveredar por essa hipótese e incorrer no erro público de adotar caminhos diferentes de alfabetização para grupos sociais distintos é uma das possibilidades. Além disso, como destaca Emilia Ferreiro (2018, p.44):

A escrita não é um produto escolar, mas sim um objeto cultural, resultado do esforço coletivo da humanidade. Como objeto cultural, a escrita cumpre diversas funções sociais e tem meios concretos de existência (especialmente nas concentrações urbanas). $O$ escrito aparece, para a criança, como objeto com propriedades específicas e como suporte de ações e intercâmbios sociais. Existem inúmeras amostras de inscrições nos mais variados contextos (letreiros, embalagens, tevê, roupas, periódicos etc.). Os adultos fazem anotações, leem cartas, comentam os periódicos, procuram um número de telefone etc. Isto é, produzem e interpretam a escrita nos mais variados contextos. É evidente que, 
por si só, a presença isolada do objeto e das ações sociais pertinentes não transmitem conhecimento, mas ambas exercem uma influência, criando as condições dentro das quais isto é possível. Imersa em um mundo onde há a presença de sistemas simbólicos socialmente elaborados, a criança procura compreender a natureza destas marcas especiais. Para tanto, não exercita uma técnica específica de aprendizagem. Como já fez antes com outros tipos de objeto, vai descobrindo as propriedades dos sistemas simbólicos por meio de um prolongado processo construtivo.

Pode-se considerar que a grande descoberta do construtivismo, qual seja, o fato de as crianças formarem hipóteses sobre a escrita que devem ser consideradas em seu processo de aquisição da linguagem letrada, não pode ser posta de lado. Não é possível voltar a discutir métodos de ensino de alfabetização, sem reconhecer que há processos cognitivos que impactam a produção do conhecimento sobre a leitura e a escrita. Os projetos de ensino da primeira leitura deverão, portanto, ser condizentes com o avanço do conhecimento sobre o ensino da leitura e da escrita; aspecto desconsiderado na atual política de alfabetização do Brasil. Retomar o debate sobre os métodos pode ser um dos pontos compreendidos em um projeto público de ensino da leitura e da escrita. Mas jamais poderá ser o único ou o principal fator a ser considerado no âmbito do referido tema. Há de se ter em conta a produção científica que, no Brasil, tem há décadas versado sobre esse assunto. Ao se fazer isso, poder-se-á finalmente olhar para o futuro com confiança e com esperança.

\section{Referências}

AZANHA, J. M. P. Uma ideia de pesquisa educacional. 2. ed. São Paulo: Edusp/Fapesp, 2011.

BRASIL. Ministério da Educação. Política Nacional de Alfabetização - PNA. Secretaria da Alfabetização. Brasília: MEC, Sealf, 2019.

BRASIL. Ministério da Educação. Tempo de aprender: formação continuada em práticas de alfabetização. Secretaria da Alfabetização. Brasília: MEC, 2020, módulo 1, episódio 3.

BRASIL. Ministério da Educação. Tempo de aprender: formação continuada em práticas de alfabetização. Secretaria da Alfabetização. Brasília: MEC, 2020, módulo 2, episódio 4.

BRASIL. Ministério da Educação. Tempo de aprender: formação continuada em práticas de alfabetização. Secretaria da Alfabetização. Brasília: MEC, 2020, módulo 2, episódio 6. 
BRASIL. Ministério da Educação. Tempo de aprender: formação continuada em práticas de alfabetização. Secretaria da Alfabetização. Brasília: MEC, 2020, módulo 3, episódio 2.

BRASLAVSKY, B. P. Problemas e métodos no ensino da leitura. Trad. Agostinho Minicucci. São Paulo: Melhoramentos; Editora da USP, 1971.

CARVALHO, M. Guia prático do alfabetizador. São Paulo: Ática, 1994.

DECROLY, O. La función de globalización y la enseñanza y otros ensaios. Madri: Editorial Biblioteca Nueva, 2006.

FERREIRO, E. Reflexões sobre alfabetização. 26. ed. São Paulo: Cortez, 2018.

HAMAÏDE, A. La méthode Decroly. Paris: Delachaux et Niestlé Éditeurs, 1976.

JACOTOT, J.-J. Enseignement universel: langue maternelle. Paris: A la Librairie Spéciale de l'Enseignement Universel, 1834.

MONTESSORI, M. A descoberta da criança: pedagogia científica. Campinas: Kírion, 2017.

MORTATTI, M. R. L. Os sentidos da alfabetização (1876/1994). São Paulo: Unesp, 2000.

NADALIM, C. As 5 etapas para alfabetizar seus filhos em casa - o guia definitivo. Brasil: Alcântara Cursos On-line, 2015.

NATIONAL READING PANEL. Teaching children to read: an evidence-based assessment of the scientific research literature on reading and its implications for reading instruction. Washington: National Institute of Child Health and Human Development, 2000.

SOARES, M. Letramento: um tema em três gêneros. Belo Horizonte: Autêntica, 1998.

SOARES, M. Alfabetização: a questão dos métodos. São Paulo: Contexto, 2018.

Recebido em novembro 2020.

Aprovado em abril 2021. 